\title{
An Efficient Experiment for Sequential Backbone Assignment of Medium-Sized Isotopically Enriched Proteins
}

\author{
STEPHAN GRZESIEK* AND AD BAX \\ Laboratory of Chemical Physics, National Institutes of Diabetes and Digestive and Kidney Diseases, \\ National Institutes of Health, Bethesda, Maryland 20892
}

Received May 1, 1992

Recently proposed triple-resonance experiments (1-14) make it possible to obtain complete backbone assignments of isotopically enriched proteins without recourse to NOE information. A main practical problem with the triple-resonance assignment approach is the necessity to record a substantial number of $3 \mathrm{D}$ spectra, each requiring typically at least one or two days of measuring time. A 4D triple-resonance approach has been proposed to remove the need for recording more than just two 4D experiments for completing the backbone assignments (11). However, if there is overlap in the ${ }^{1} \mathrm{H}_{\alpha}-{ }^{13} \mathrm{C}_{\alpha}$ region of the $2 \mathrm{D}$ spectrum, these and other (12) $4 \mathrm{D}$ experiments also do not offer unique connections between sequential amides. In cases of such overlap, an experiment that relays magnetization from the amide to the intraresidue carbonyl can resolve the ambiguity caused by the $\mathrm{C}_{\alpha}-\mathrm{H}_{\alpha}$ degeneracy (13). Alternatively, an experiment named $\mathrm{CBCA}(\mathrm{CO}) \mathrm{NH}$, which correlates amide signals with the $\mathrm{C}_{\alpha}$ and $\mathrm{C}_{\beta}$ resonances of the preceding residue by using relay via the intervening ${ }^{13} \mathrm{CO}$ nucleus, provides information on the type of amino acid preceding each amide and thus frequently resolves the ambiguity caused by $\mathrm{C}_{\alpha}-\mathrm{H}_{\alpha}$ degeneracy (14). Here we describe a similar experiment, named $\mathrm{CBCANH}$, which correlates the amide ${ }^{1} \mathrm{H}$ and ${ }^{15} \mathrm{~N}$ signals with both the intraresidue $C_{\alpha}$ and $C_{\beta}$ signals and with the $C_{\alpha}$ and $C_{\beta}$ of the preceding residue. For small- and medium-sized proteins, up to $\sim 20 \mathrm{kDa}$, this $3 \mathrm{D}$ experiment alone can yield virtually complete assignments of the backbone and the $\mathrm{C}_{\beta}$ resonances.

The pulse scheme for the CBCANH experiment is sketched in Fig. 1. Before describing the experiment in more detail, we first outline its general mechanism. An INEPT transfer enhances polarization of both $C_{\alpha}$ and $C_{\beta}$ spins. Chemical shifts of both $\mathrm{C}_{\alpha}$ and $\mathrm{C}_{\beta}$ are encoded during the constant-time evolution period, $2 T_{\mathrm{AB}}(7,8$, 10, 14). When the $90^{\circ}{ }^{13} \mathrm{C}$ pulse is applied, at time $\mathrm{b}$ in Fig. $1, \mathrm{C}_{\beta}$ magnetization is transferred to $\mathrm{C}_{\alpha}$, but at the same time a fraction of $\mathrm{C}_{\alpha}$ magnetization remains on $\mathrm{C}_{\alpha}$. Subsequently, $C_{\alpha}$ magnetization is transferred to its intraresidue ${ }^{15} \mathrm{~N}$ and to the ${ }^{15} \mathrm{~N}$ of the next residue, via the ${ }^{1} J_{\mathrm{C} \alpha \mathrm{N}}$ and ${ }^{2} J_{\mathrm{C} \alpha \mathrm{N}}$ couplings, respectively. Following a constant-time ${ }^{15} \mathrm{~N}$ evolution period, the ${ }^{15} \mathrm{~N}$ magnetization is transferred to the amide protons with a reverse INEPT sequence, prior to detection of the $H_{N}$ signals.

* On leave from F. Hoffmann-LaRoche Itd., Basel, Switzerland. 


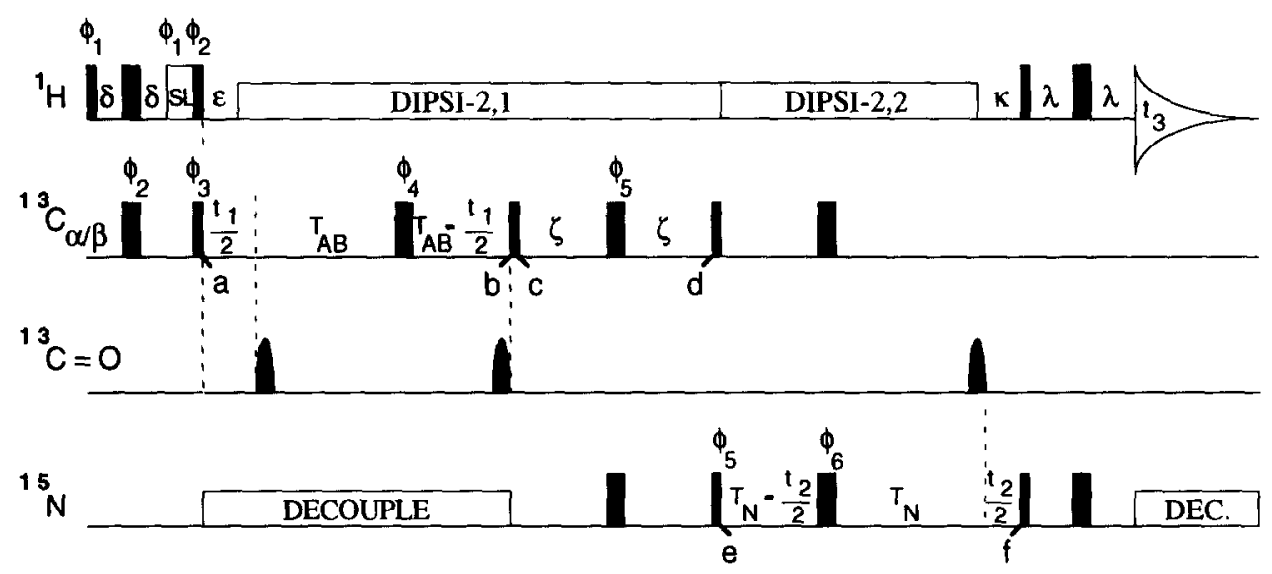

FIG. 1. Pulse scheme of the CBCANH experiment. Narrow and wide pulses correspond to $90^{\circ}$ and $180^{\circ}$ flip angles, respectively. Pulses for which the phase is not indicated are applied along the $x$ axis. The ${ }^{1} \mathrm{H}$ carrier is set to the $\mathrm{H}_{2} \mathrm{O}$ frequency for the first part of the pulse sequence, up to time $\mathrm{d}$, and switched to the center of the amide region $\left(8.4 \mathrm{ppm}\right.$ ) thereafter. Thus, the frequency of the ${ }^{1} \mathrm{H}$ broadband decoupling (with a $5 \mathrm{kHz}$ RF field) is switched at this point, and the two modes of decoupling, using a coherent DIPSI-2 scheme (22), are marked DIPSI-2,1 and DIPSI-2,2. ${ }^{15} \mathrm{~N}$ decoupling is accomplished using WALTZ-16 modulation with a $1.5 \mathrm{kHz}$ RF field. Carbonyl pulses have a shaped amplitude profile, corresponding to the center lobe of a $\sin x / x$ function and a duration of $202 \mu \mathrm{s}$. The carrier for the $\mathrm{C}_{\alpha / \beta}$ pulses is positioned at $46 \mathrm{ppm}$, and the power of the $180^{\circ}{ }^{13} \mathrm{C}_{\alpha / \beta}$ pulses is adjusted such that they do not excite the ${ }^{13} \mathrm{CO}$ nuclei (11.5 kHz RF ficld for $150.9 \mathrm{MHz}{ }^{13} \mathrm{C}$ frequency). Phase cycling is as follows: $\phi_{1}=y ; \phi_{2}=x,-x ; \phi_{3}=x$; $\phi_{4}=8(x), 8(y), 8(-x), 8(-y) ; \phi_{5}=2(x), 2(-x) ; \phi_{6}=4(x), 4(-x) ;$ Acq. $=x, 2(-x), 2(x), 2(-x), x,-x$, $2(x), 2(-x), 2(x),-x$. Quadrature in the $t_{1}$ and $t_{2}$ domains is obtained by changing the phases $\phi_{3}$ and $\phi_{5}$, respectively, in the usual States-TPPI manner (14). Delay durations are $\delta=1.5 \mathrm{~ms} ; \mathrm{t}-2.1 \mathrm{~ms} ; T_{\mathrm{AB}}-3.3$ $\mathrm{ms} ; \zeta=11 \mathrm{~ms} ; T_{\mathrm{N}}=11.2 \mathrm{~ms} ; \kappa=5.4 \mathrm{~ms} ; \lambda=2.25 \mathrm{~ms}$.

The relevant terms of the magnetization-transfer pathway can be conveniently expressed in terms of the product-operator formalism (15). For clarity, relaxation terms are not included and constant multiplicative factors are omitted. Only terms that result in observable magnetization during the detection period, $t_{3}$, are retained. The spin operators used are $B$ for $\mathrm{C}_{\beta}, A$ for $\mathrm{C}_{\alpha}, \mathrm{N}_{1}$ for the intraresidue ${ }^{15} \mathrm{~N}$ spin, and $\mathrm{N}_{2}$ for the ${ }^{15} \mathrm{~N}$ spin of the succeeding residue. The two amide protons attached to these two ${ }^{15} \mathrm{~N}$ nuclei are labeled $\mathrm{H}_{1}$ and $\mathrm{H}_{2}$, respectively. The resonance offset of a nucleus, $\mathrm{X}$, is denoted $\delta_{\mathrm{X}}$.

The first INEPT part of the pulse sequence, which includes a water-purge pulsed labeled SL (16), transfers ${ }^{1} \mathrm{H}$ magnetization into antiphase ${ }^{13} \mathrm{C}_{\alpha}$ and ${ }^{13} \mathrm{C}_{\beta}$ magnetization (time a). Refocusing of this antiphase magnetization follows a different time dependence for methine, methylene, and methyl carbons. A compromise value of $2.1 \mathrm{~ms}$ (17) was used for this refocusing delay, $\epsilon$, in the scheme in Fig. 1.

In the $\mathrm{C}_{\alpha} / \mathrm{C}_{\beta}$ constant-time evolution period (between points a and $\mathrm{b}$ ), of total duration $2 T_{\mathrm{AB}}=6.6 \mathrm{~ms}$, the effect of $J$ coupling to carbonyl carbons is eliminated by applying a selective ${ }^{13} \mathrm{CO}$ pulse at time $t_{1} / 2$ after the ${ }^{13} \mathrm{C}_{\phi 3}$ pulse and by adjusting the power of the $180_{\phi 4}^{\circ}$ pulse in such a way that it does not excite the ${ }^{13} \mathrm{CO}$ resonances. During this period, evolution of the transverse $\mathrm{C}_{\alpha}$ and $\mathrm{C}_{\beta}$ magnetization, refocused with respect to its attached proton(s), is then described by 


$$
\begin{aligned}
& A_{x} \rightarrow A_{x} \cos ^{m}\left(2 \pi J_{\mathrm{AB}} T_{\mathrm{AB}}\right) \cos \left(2 \pi \delta_{\mathrm{A}} t_{1}\right) \\
& B_{x} \rightarrow B_{y} A_{z} \sin \left(2 \pi J_{\mathrm{AB}} T_{\mathrm{AB}}\right) \cos ^{n}\left(2 \pi J_{\mathrm{BC}} T_{\mathrm{AB}}\right) \cos \left(2 \pi \delta_{\mathrm{B}} t_{1}\right),
\end{aligned}
$$

where $J_{\mathrm{AB}}$ and $J_{\mathrm{BC}}$ are the $\mathrm{C}_{\alpha}-\mathrm{C}_{\beta}$ and $\mathrm{C}_{\beta}-\mathrm{C}_{\gamma}$ one-bond $J$ couplings, and the exponent $m$ is 0 for glycine and 1 for all other residues. The exponent $n$ is 2 for valine and isoleucine, 0 for alanine, aspartic acid, asparagine, and serine, and 1 for all other resiclues. The second shaped ${ }^{13} \mathrm{CO}$ pulse, applied just before time $\mathrm{b}$, merely serves to eliminate the phase error induced by a Bloch-Siegert effect (18) of the first shaped $180^{\circ}{ }^{13} \mathrm{CO}$ pulse on the transverse $C_{\alpha} / C_{\beta}$ magnetization, ensuring a pure cosinusoidal modulation in the $t_{1}$ dimension. Temporarily omitting the trigonometric terms from Eq.[1], the $90_{x}^{\circ} C_{\alpha} / C_{\beta}$ pulse at point $\mathrm{b}$ converts these terms according to

$$
\begin{aligned}
A_{x} & \rightarrow A_{x} \\
B_{y} A_{z} & \rightarrow B_{z} A_{y} .
\end{aligned}
$$

During the rephasing/dephasing interval, between time points $\mathrm{c}$ and $\mathrm{d}, \mathrm{C}_{\alpha}$ magnetization of [2b] rephases with respect to spin $B$, whereas [2a] partially dephases. At the same time, dephasing of $\mathrm{C}_{\alpha}$ magnetization caused by coupling to the intraresidue ${ }^{15} \mathrm{~N}$ spin and to the ${ }^{15} \mathrm{~N}$ of the next residue takes place. These processes are described by

$$
\begin{aligned}
A_{x} \rightarrow A_{y} N_{1 z} \sin \left(2 \pi J_{\mathrm{N} 1 \mathrm{~A}} \zeta\right) & \cos \left(2 \pi J_{\mathrm{N} 2 \mathrm{~A}} \zeta\right) \cos ^{m}\left(2 \pi J_{\mathrm{AB}} \zeta\right) \\
& +A_{y} N_{2 z} \sin \left(2 \pi J_{\mathrm{N} 2 \mathrm{~A}} \zeta\right) \cos \left(2 \pi J_{\mathrm{N} 1 \mathrm{~A}} \zeta\right) \cos ^{m}\left(2 \pi J_{\mathrm{AB}} \zeta\right) \\
B_{z} A_{y} \rightarrow A_{y} N_{1 z} \sin \left(2 \pi J_{\mathrm{N} 1 \mathrm{~A}} \zeta\right) & \cos \left(2 \pi J_{\mathrm{N} 2 \mathrm{~A}} \zeta\right) \sin \left(2 \pi J_{\mathrm{AB}} \zeta\right) \\
& +A_{y} N_{2 z} \sin \left(2 \pi J_{\mathrm{N} 2 \mathrm{~A}} \zeta\right) \cos \left(2 \pi J_{\mathrm{N} 1 \mathrm{~A}} \zeta\right) \sin \left(2 \pi J_{\mathrm{AB}} \zeta\right)
\end{aligned}
$$

Apart from the trigonometric coefficients, terms originating from $\mathrm{C}_{\alpha}$ and $\mathrm{C}_{\beta}$ magnetization are indistinguishable at this time, and we need to consider only the fate of either $A_{y} N_{1 z}$ or $A_{y} N_{2 z}$ to describe the remainder of the pulse sequence.

At time $\mathrm{d}$ the pair of simultaneous $90^{\circ}{ }^{13} \mathrm{C}_{\alpha} /{ }^{15} \mathrm{~N}$ pulses transforms the antiphase $\mathrm{C}_{\alpha}$ magnetization according to

$$
\begin{aligned}
& A_{y} N_{1 z} \rightarrow A_{z} N_{1 y} \\
& A_{y} N_{2 z} \rightarrow A_{z} N_{2 y} .
\end{aligned}
$$

During the subsequent ${ }^{15} \mathrm{~N}$ constant-time evolution period, of total duration $2 T_{\mathrm{N}}$, the $A_{z} N_{1 y}$ term rephases with respect to its $\mathrm{C}_{\alpha}$ coupling partner, but dephases because of the coupling via ${ }^{2} J_{\mathrm{N} I \mathrm{C} \alpha}$ to its preceding $\mathrm{C}_{\alpha}$ (note that this $\mathrm{C}_{\alpha}$ is not the spin labeled A, but the $\mathrm{C}_{\alpha}$ of the preceding residuc). The effcct of the ${ }^{13} \mathrm{CO}-{ }^{15} \mathrm{~N} J$ coupling is eliminated during the first $2 T_{\mathrm{N}}-t_{2}$ fraction of the ${ }^{15} \mathrm{~N}$ evolution period by the $180^{\circ}$ ${ }^{15} \mathrm{~N}$ pulse and by the fact that the $180^{\circ} \mathrm{C}_{\alpha} / \mathrm{C}_{\beta}$ pulse is adjusted such that it does not excite the carbonyl spins. During the last fraction, $t_{2}$, of the constant-time ${ }^{15} \mathrm{~N}$ evolution period, the shaped $180^{\circ}{ }^{13} \mathrm{CO}$ pulse decouples the ${ }^{15} \mathrm{~N} /{ }^{13} \mathrm{CO}$ interaction and evolution caused by the ${ }^{15} \mathrm{~N}$ chemical shift takes place. During the delay, $\kappa,{ }^{1} \mathrm{H}$ decoupling is switched off and ${ }^{15} \mathrm{~N}$ magnetization becomes antiphase with respect to its attached proton spin. These effects are all summarized by 


$$
\begin{aligned}
& N_{1 y} A_{z} \rightarrow N_{1 y} H_{1 z} \sin \left(2 \pi J_{\mathrm{N} 1 \mathrm{~A}} T_{\mathrm{N}}\right) \cos \left(2 \pi J_{\mathrm{N} 1 \mathrm{C} \alpha} T_{\mathrm{N}}\right) \sin \left(\pi J_{\mathrm{N} 1 \mathrm{H} 1} \kappa\right) \cos \left(2 \pi \delta_{\mathrm{N} 1} t_{2}\right) \\
& N_{2 y} A_{z} \rightarrow N_{2 y} H_{2 z} \sin \left(2 \pi J_{\mathrm{N} 2 \mathrm{~A}} T_{\mathrm{N}}\right) \cos \left(2 \pi J_{\mathrm{N} 2 \mathrm{C} \alpha} T_{\mathrm{N}}\right) \sin \left(\pi J_{\mathrm{N} 2 \mathrm{H} 2} \kappa\right) \cos \left(2 \pi \delta_{\mathrm{N} 2} t_{2}\right)
\end{aligned}
$$

${ }^{1} J_{\mathrm{NH}}$ is quite uniform in proteins and typically falls in the $92-94 \mathrm{~Hz}$ range. With $\kappa=$ $5.4 \mathrm{~ms}$, the $\sin \left(\pi J_{\mathrm{N} 1 \mathrm{H} 1} \kappa\right)$ and $\sin \left(\pi J_{\mathrm{N} 2 \mathrm{H} 2^{K}}\right)$ terms in Eq. [5] are very close to 1 and therefore can be safely omitted. $J_{\mathrm{NIC} \alpha}$ is the two-bond coupling between $\mathrm{N}_{1}$ and the $\mathrm{C}_{\alpha}$ of the preceding residue and $J_{\mathrm{N} 2 \mathrm{C} \alpha}$ is the one-bond coupling between $\mathrm{N}_{2}$ and its intraresidue $\mathrm{C}_{\alpha}$.

The final reverse INEPT, applied following time f, transforms $N_{1 y} H_{1 z}$ into $H_{1 x}$ and $N_{2 y} H_{2 z}$ into $H_{2 x}$, which are both observed during the detection period, $t_{3}$. As is clear from the above, for a given amide proton, the CBCANH experiment yields correlations to its intraresidue $\mathrm{C}_{\alpha}$ and $\mathrm{C}_{\beta}$ nuclei and to the $\mathrm{C}_{\alpha}$ and $\mathrm{C}_{\beta}$ of the preceding residue. Neglecting losses during the first INEPT and the final reverse INEPT, the amplitudes of the four corresponding cross peaks are obtained by combining the trigonometric terms of Eqs. [1], [3], and [5]:

$$
\begin{aligned}
& A \rightarrow H_{1 x} \cos ^{m}\left(2 \pi J_{\mathrm{AB}} T_{\mathrm{AB}}\right) \sin \left(2 \pi J_{\mathrm{N} 1 \mathrm{~A}} \zeta\right) \cos \left(2 \pi J_{\mathrm{N} 2 \mathrm{~A}} \zeta\right) \cos ^{m}\left(2 \pi J_{\mathrm{AB}} \zeta\right) \sin \left(2 \pi J_{\mathrm{N} 1 \mathrm{~A}} T_{\mathrm{N}}\right) \\
& \times \cos \left(2 \pi J_{\mathrm{N} 1 \mathrm{C} \alpha} T_{\mathrm{N}}\right) \cos \left(2 \pi \delta_{\mathrm{A}} t_{1}\right) \cos \left(2 \pi \delta_{\mathrm{N} 1} t_{2}\right) \quad[6 \mathrm{a}] \\
& A \rightarrow H_{2 x} \cos ^{m}\left(2 \pi J_{\mathrm{AB}} T_{\mathrm{AB}}\right) \sin \left(2 \pi J_{\mathrm{N} 2 \mathrm{~A}} \zeta\right) \cos \left(2 \pi J_{\mathrm{N} 1 \mathrm{~A}} \zeta\right) \cos ^{m}\left(2 \pi J_{\mathrm{AB}} \zeta\right) \sin \left(2 \pi J_{\mathrm{N} 2 \mathrm{~A}} T_{\mathrm{N}}\right) \\
& \times \cos \left(2 \pi J_{\mathrm{N} 2 C_{\alpha}} T_{\mathrm{N}}\right) \cos \left(2 \pi \delta_{\mathrm{A}} t_{1}\right) \cos \left(2 \pi \delta_{\mathrm{N} 2} t_{2}\right) \\
& B \rightarrow H_{\mathrm{Lx}} \sin \left(2 \pi J_{\mathrm{AB}} T_{\mathrm{AB}}\right) \cos ^{n}\left(2 \pi J_{\mathrm{BC}} T_{\mathrm{AB}}\right) \sin \left(2 \pi J_{\mathrm{N} 1 \mathrm{~A}} \zeta\right) \cos \left(2 \pi J_{\mathrm{N} 2 \mathrm{~A}} \zeta\right) \sin \left(2 \pi J_{\mathrm{AB}} \zeta\right) \\
& \times \sin \left(2 \pi J_{\mathrm{N} 1 \mathrm{~A}} T_{\mathrm{N}}\right) \cos \left(2 \pi J_{\mathrm{N} 1 C_{\alpha}} T_{\mathrm{N}}\right) \cos \left(2 \pi \delta_{\mathrm{B}} t_{1}\right) \cos \left(2 \pi \delta_{\mathrm{N} 1} t_{2}\right) \quad[6 \mathrm{c}] \\
& B \rightarrow H_{2 x} \sin \left(2 \pi J_{\mathrm{AB}} T_{\mathrm{AB}}\right) \cos ^{n}\left(2 \pi J_{\mathrm{BC}} T_{\mathrm{AB}}\right) \sin \left(2 \pi J_{\mathrm{N} 2 \mathrm{~A}} \zeta\right) \cos \left(2 \pi J_{\mathrm{N} 1 \mathrm{~A}} \zeta\right) \sin \left(2 \pi J_{\mathrm{AB}} \zeta\right) \\
& \times \sin \left(2 \pi J_{\mathrm{N} 2 \mathrm{~A}} T_{\mathrm{N}}\right) \cos \left(2 \pi J_{\mathrm{N} 2 \mathrm{C}_{\alpha}} T_{\mathrm{N}}\right) \cos \left(2 \pi \delta_{\mathrm{B}} t_{1}\right) \cos \left(2 \pi \delta_{\mathrm{N} 2} t_{2}\right) .
\end{aligned}
$$

$J_{\mathrm{C}_{\alpha} \beta}$ couplings fall in the $35-40 \mathrm{~Hz}$ range, ${ }^{1} J_{\mathrm{NC} \alpha}$ falls in the $9-12.5 \mathrm{~Hz}$ range, and $J_{\mathrm{NC} \alpha}$ falls in the 6-9 Hz. range (19). Based on these values, Eq.[6] indicates that significant intensities are expected for all four correlations if $T_{\mathrm{AB}}=3.3 \mathrm{~ms}, \zeta=11$ $\mathrm{ms}$, and $T_{\mathrm{N}}=11 \mathrm{~ms}$. If $T_{\mathrm{N}}=11 \mathrm{~ms}$ does not allow for a sufficiently long ${ }^{15} \mathrm{~N}$ constanttime evolution period, i.e., the ${ }^{15} \mathrm{~N}$ resolution obtainable with $T_{\mathrm{N}}=11 \mathrm{~ms}$ is lower than required, a value that is $r$ ms longer can be used by applying the ${ }^{13} C_{\alpha / \beta}$ pulse $r$ ms after the $180_{\phi 6}^{\circ}{ }^{15} \mathrm{~N}$ pulse.

The CBCANH experiment is demonstrated for a sample containing $1.5 \mathrm{mM}$ calmodulin, saturated with $\mathrm{Ca}^{2+}$ and complexed with a 26-residue peptide fragment of skeletal muscle myosin light chain kinase. Total molecular weight of the complex is $20 \mathrm{kDa}$. Experiments are recorded at $600 \mathrm{MHz}{ }^{1} \mathrm{H}$ frequency on a Bruker AMX-600, operating at $35^{\circ} \mathrm{C}$. A $3 \mathrm{D}$ time-domain matrix consisting of $52 *\left(t_{1},{ }^{13} \mathrm{C}\right) \times 32^{*}\left(t_{2}\right.$, $\left.{ }^{15} \mathrm{~N}\right) \times 512 *\left(t_{3},{ }^{1} \mathrm{H}\right)$ data points was recorded, where $N^{*}$ refers to $N$ complex data points. Acquisition times were $6.16 \mathrm{~ms}\left(t_{1}\right), 21.12 \mathrm{~ms}\left(t_{2}\right)$, and $55.3 \mathrm{~ms}\left(t_{3}\right)$. For each pair of $t_{1} / t_{2}$ values 192 scans were recorded, and the total acquisition time was $\sim 93$ hours. Mirror image linear prediction $(20)$ was used to extend the time domain data to $128^{*}$ in the $t_{1}$ dimension and to $64^{*}$ in the $t_{2}$ dimension, prior to cosine-squared bell apodization in the $t_{1}$ and $t_{2}$ dimensions and Fourier transformation. The absorptive part of the final 3D matrix corresponds to $256 \times 128 \times 1024$ data points. 
Figure 2 shows strips taken through the 3D CBCANH spectrum for residues Glu54Phe65. Each strip represents a narrow $F_{3}$ region of an $F_{1} / F_{3}$ cross section of the 3D spectrum at the ${ }^{1} \mathrm{H} /{ }^{15} \mathrm{~N}$ frequency of an amino acid. Thus, each strip displays the $\mathrm{C}_{\alpha}$ and $\mathrm{C}_{\beta}$ correlations observed for the amide of a given residue. As can be seen in Fig. 2 , except for the two glycine residues and the two residues following these glycines, all amides show the four expected correlations to both the intraresidue $\mathrm{C}_{\alpha}$ and $\mathrm{C}_{\beta}$ and to the $\mathrm{C}_{\alpha}$ and $\mathrm{C}_{\beta}$ of the preceding residue. These latter correlations are marked by solid dots and can be tentatively differentiated from the intraresidue ones by their weaker intensities (caused by the smaller value of ${ }^{2} J_{\mathrm{NC} \alpha}$ compared to that of ${ }^{1} J_{\mathrm{NC} \alpha}$ ), or can be unambiguously identified using the $\mathrm{CBCA}(\mathrm{CO}) \mathrm{NH}$ relay experiment, described elsewhere (14).

$C_{\alpha}$ resonances of glycines and $C_{\beta}$ resonances of all other residues are opposite in phase relative to the other $\mathrm{C}_{\alpha}$ correlations in Fig. 2. This is caused by the fact that $\cos \left(2 \pi J_{\mathrm{AB}} \zeta\right)$ in Eq. [6] is negative and opposite in $\operatorname{sign}$ to $\sin \left(2 \pi J_{\mathrm{AB}} \zeta\right)$. This feature is useful for discriminating between $\mathrm{C}_{\alpha}$ and $\mathrm{C}_{\beta}$ resonances of serine residues, which can resonate in the same spectral region.

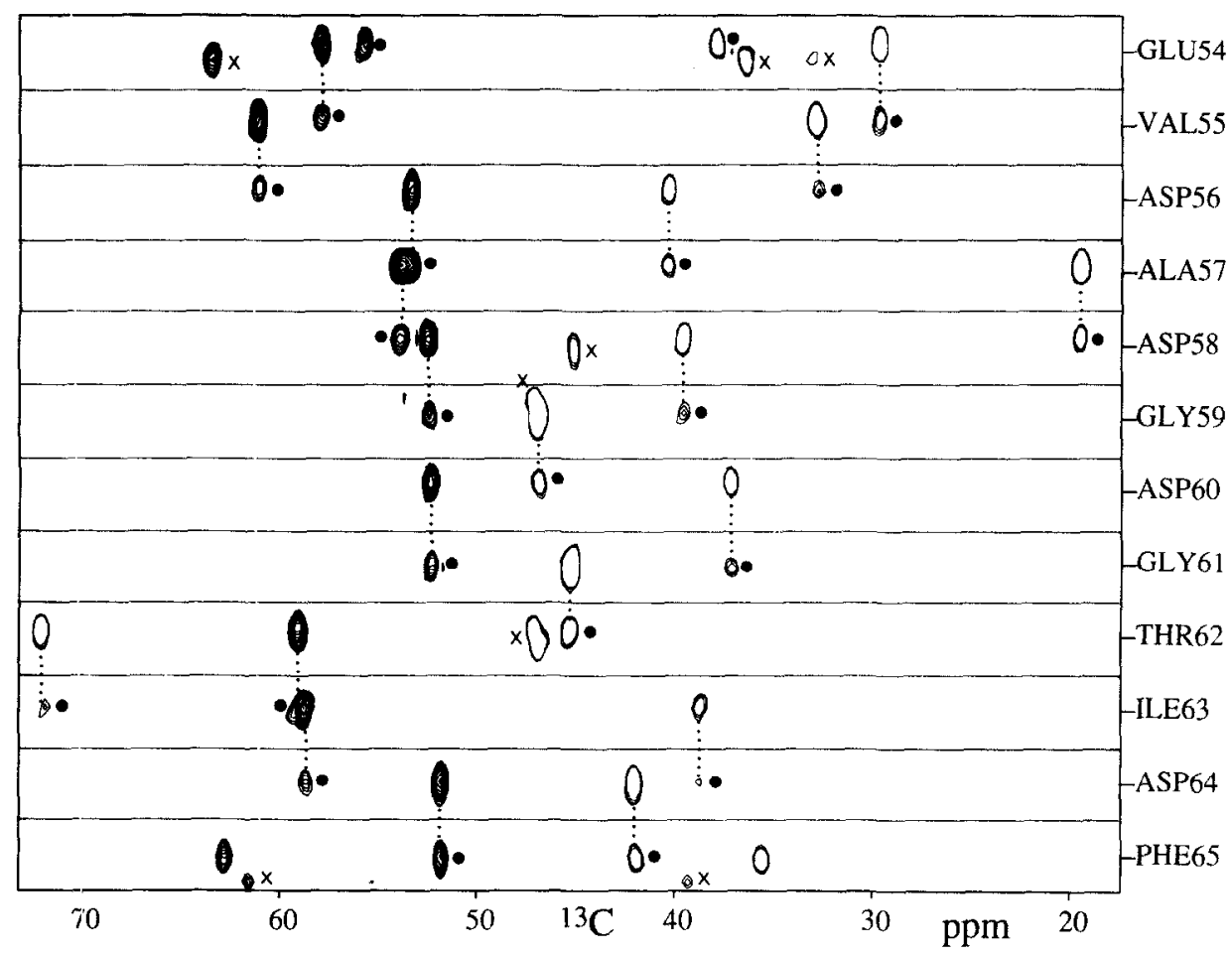

FIG. 2. Strip plot of the correlations observed for the amides of residues Glu54-Phe65 of a calmodulinpeptide complex. Each amide correlates with its intraresidue $C_{\alpha}$ and $C_{\beta}$ nuclei and with the $C_{\alpha}$ and $C_{\beta}$ of the preceding residue. Interresidue connectivities are marked by solid dots. Negative peaks, corresponding to $C_{\beta}$ resonances and to $C_{\alpha}$ of glycine residues, are displayed with a maximum of three contours. Peaks marked " $X$ " correspond to correlations to amide ${ }^{1} \mathrm{H}-{ }^{15} \mathrm{~N}$ pairs that are close in frequency to that for which the strip has been selected. 
The CBCANH experiment is particularly powerful for making sequential backbone and $\mathrm{C}_{\beta}$ assignments in isotopically enriched proteins because two independent connectivity pathways, marked by dotted lines in Fig. 2, are available in the same spectrum. As chemical-shift dispersion, on average, is even better for $\mathrm{C}_{\beta}$ than for $\mathrm{C}_{\alpha}$, the CBCANH spectrum yields a large number of unambiguous connectivities between sequential amino acids. Moreover, the unique $\mathrm{C}_{\alpha}$ and $\mathrm{C}_{\beta}$ shifts of glycine, threonine, serine, and alanine residues immediately identify the amides of these residues. For other amides, combined knowledge of both the intraresidue $\mathrm{C}_{\alpha}$ and $\mathrm{C}_{\beta}$ shifts frequently narrows down the possible residue types to only a small number. This extensive knowledge of residue type generally will solve ambiguities that may occur for two residues with identical $\mathrm{C}_{\alpha}$ chemical shifts and degenerate $\mathrm{C}_{\beta}$ shifts. Therefore, the CBCANH spectrum alone, or combined with the $\mathrm{CBCA}(\mathrm{CO}) \mathrm{NH}$ spectrum, provides sufficient information for making complete backbone assignments of isotopically enriched proteins. Analysis of the CBCANH spectrum indicated that residues Glu83 and Glu84 as well as Glu 7 and Glu 14 had been interchanged in the original assignment (21).

In contrast to the $\mathrm{CBCA}(\mathrm{CO}) \mathrm{NH}$ experiment, which has been applied successfully to a $31 \mathrm{kDa}$ protein (14), a major limitation of the CBCANH experiment is its relatively low sensitivity, which is affected most strongly by the transverse relaxation of $\mathrm{C}_{\alpha}$ magnetization during the relatively long dephasing period, $2 \zeta$. For this reason, we expect that the CBCANH experiment will rapidly decrease in effectiveness for proteins larger than $\sim 20 \mathrm{kDa}$. For Gln3 through Lys 148 of the $20 \mathrm{kDa}$ calmodulin-peptide complex, only two $\mathrm{II}_{\mathrm{N}}-\mathrm{C}_{\alpha, i}$, six $\mathrm{H}_{\mathrm{N}}-\mathrm{C}_{\alpha, i-1}$, no $\mathrm{C}_{\beta, i}$, and eight $\mathrm{C}_{\beta, i-1}$ correlations were below the noise threshold. For isotopically enriched proteins of up to $\sim 20 \mathrm{kDa}$, the CBCANH experiment is therefore probably the most effective single method for obtaining sequential resonance assignments published to date.

\section{ACKNOWLEDGMENTS}

This work was supported by the AIDS Targeted Anti-Viral Program of the Office of the Director of the National Institutes of Health. S.G. acknowledges funding by the ROCHE Research Foundation.

\section{REFERENCES}

1. M. IKURA, L. E. KAY, AND A. BAX, Biochemistry 29, 4659 (1990).

2. W. P. Niemczura, G. L. Helms, A. S. Chesnick, R. E. Moore, and V. Bornemann, J. Magn. Reson. 81, 635 (1989).

3. L. E. KAY, M. IKURA, R. TsChudin, AND A. BAX, J. Magn. Reson. 89, 596 (1990).

4. B. J. Stockman, M. D. ReIlly, W. M. Westler, E. L. Ulrich, AND J. L. Markley, Biochemistry 28, 230 (1989).

5. L. E. KAY, M. IKURA, AND A. BAX, J. Magn. Reson. 91, 84 (1991).

6. A. BAX AND M. IKURA, J. Biomol. NMR 1, 99 (1991).

7. R. Powers, A. M. Gronenborn, G. M. Clore, and A. BaX, J. Magn. Reson. 94, 209 (1991).

8. A. G. Palmer III, W. J. Fairbrother, J. Cavanagh, P. E. Wright, and M. RanCe, J. Biomol. NMR 2, 103 (1992).

9. B. T. FARMer II, R. A. Venters, L. D. SPiCER, M. G. WitTekind, AND L. MÚller, J. Biomol. NMR 2, 195 (1992).

10. S. GRZESIEK AND A. BAX, J. Magn. Reson. 96, 432 (1992).

11. W. Boucher, E. D. Laue, S. Campbell-Burk, and P. J. Domaille, J. Am. Chem. Soc. 114, 2262 (1992).

12. L. E. Kay, M. IKuRa, G. ZhU, AND A. BAX, J. Magn. Reson. 91, 422 (1991).

13. R. T. Clubb, V. Thanabal, AND G. Wagner, J. Magn. Reson. 97, 213 (1992). 
14. S. GRZESIEK AND A. BaX, J. Am. Chem. Soc., submitted.

15. R. R. ERnst, G. Bodenhausen, ANd A. Wokaun, "Principles of Nuclear Magnetic Resonance in One and Two Dimensions," pp. 25-29, Clarendon Press, Oxford, 1987.

16. B. A. Messerle, G. Wider, G. Otting, C. Weber, AND K. WUThrich, J. Magn. Reson. 85, 608 (1989).

17. D. P. Burum AND R. R. ERnst, J. Magn. Reson. 39, 163 (1980).

18. R. FreEman, "A Handbook of Nuclear Magnetic Resonance," p. 14, Wiley, New York, 1988.

19. F. Delaglio, D. A. Torchia, AND A. BaX, J. Biomol. NMR 1, 439 (1991).

20. G. ZHU AND A. BAX, J. Magn. Reson. 90, 405 (1990).

21. M. IKURA, L. E. KAY, M. KRINKS, AND A. BAX, Biochemistry 30, 5498 (1991).

22. A. J. Shaka, C. J. LeE, ANd A. Pines, J. Magn. Reson. 77, 274 (1988). 